\title{
ADAM17 promotes lymph node metastasis in gastric cancer via activation of the Notch and Wnt signaling pathways
}

\author{
WEI LI, DAGUANG WANG, XUAN SUN, YANG ZHANG, LEI WANG and JIAN SUO \\ Department of Gastrointestinal Surgery, The First Hospital of Jilin University, Changchun, Jilin 130021, P.R. China
}

Received January 29, 2018; Accepted November 26, 2018

DOI: $10.3892 / \mathrm{ijmm} .2018 .4028$

\begin{abstract}
Disintegrin and metalloproteinase domaincontaining proteins (ADAMs) have been implicated in cell adhesion, signaling and migration. The aim of the present study was to identify key members of the ADAM protein family associated with the metastasis of gastric cancer and to evaluate their clinical significance. A total of 193 patients with gastric cancer and positive lymph node metastasis were enrolled. Key members of the ADAM family associated with lymph node metastasis were identified. The correlations between survival times and the clinicopathological features of patients were investigated. Furthermore, ADAM17 expression in gastric cancer cells with different metastatic potentials was determined. ADAM17 was overexpressed in BGC-823 cells and suppressed in SGC-7901 cells to further investigate its effects on cell viability and migration. The key pathways associated with ADAM17 were identified by gene set enrichment analysis (GSEA). It was found that ADAM9 and ADAM17 were significantly upregulated in gastric cancer and positive metastatic lymph node tissues. Further, there was a strong correlation between the survival times of patients and ADAM17 expression. ADAM17 was upregulated in gastric cancer cells with high metastatic potential. The viability of BGC-823 cells significantly increased following ADAM17 overexpression, whereas the viability and migration of SGC-7901 cells decreased following ADAM17 suppression. GSEA and western blot analysis revealed a positive correlation between the Notch and Wnt signaling pathways with ADAM17 expression. In conclusion, the increased expression of ADAM17 promoted the progression of gastric cancer, potentially via Notch and/or Wnt signaling pathway activation, and ADAM17 may serve as a useful prognostic marker.
\end{abstract}

Correspondence to: Dr Jian Suo or Dr Daguang Wang, Department of Gastrointestinal Surgery, The First Hospital of Jilin University, 71 Xinmin Street, Changchun, Jilin 130021, P.R. China

E-mail: suojian42@gmail.com

E-mail: daguangjida@163.com

Key words: gastric cancer, lymph node metastasis, disintegrin and metalloproteinase domain-containing protein 17 , prognostic factor, signaling pathway

\section{Introduction}

Gastric cancer is one of the most common malignancies, with a substantial impact on global health (1-3). During its early stages, it is either asymptomatic or presents with nonspecific symptoms. Therefore, gastric cancer often reaches an advanced stage prior to diagnosis and poses a major clinical challenge with poor patient outcomes (4-6). In addition, there are limited efficacious therapeutic strategies for treating advanced gastric cancer $(7,8)$, and the molecular mechanisms underlying gastric cancer progression remain unclear. Thus, elucidating the key molecular mechanisms will aid in the development of novel therapeutic targets for this disease.

Disintegrin and metalloproteinase domain-containing proteins (ADAMs) are a family of multidomain transmembrane glycoproteins, which are widely implicated in cell adhesion, cell-cell signaling and cell migration $(9,10)$. The diverse roles of ADAMs in the pathological processes of various human cancers have gained increasing attention. In gastric cancer, ADAM33 affects cell migration and proliferation by regulating the secretion of interleukin-18 (11). ADAM9, 12 , and 15 are expressed at higher levels in gastric cancer cells, compared with non-neoplastic foveolar epithelial cells, and have been implicated in the malignant growth of gastric cancer (12). ADAM10 may serve as a useful prognostic marker for predicting gastric cancer progression, as ADAM10 expression correlates with lymph node and distant metastases (13). Although efforts have been made, a higher priority must be given to further investigate key members of the ADAM family that are associated with tumor metastasis and are of prognostic significance for patients with gastric cancer.

ADAM17 (also known as TNF- $\alpha$-converting-enzyme) has been identified to function as a signaling scissor in the tumor microenvironment (14) and thus contributes to tumorigenesis and tumor progression $(15,16)$. The dysregulation of ADAM17 expression and its crucial role in the pathology of various cancers has been widely revealed. For instance, increased ADAM17 expression is associated with aggressive progression of non-small cell lung cancer (17). ADAM17 silencing suppresses cancer cell growth autonomy and inhibits tissue invasion (18). Further, ADAM17 promotes breast cancer tumorigenesis and progression by regulating cell proliferation, angiogenesis, invasion and apoptosis (19). Notably, ADAM17 was found to be upregulated in gastric cancer, and this increased expression contributed to tumor 
progression and resulted in poor prognosis; ADAM17 may therefore be an independent factor to predict tumor prognosis (20,21). In addition, microRNA (miR)-338-3p has been shown to suppress the proliferation, migration and invasion of gastric cancer cells through downregulation of ADAM17 (22). ADAM17 expression is upregulated by forkhead box protein M1 and consequently promotes the proliferation and tumor growth of gastric cancer cells (23). Additionally, ADAM17 promotes epithelial-mesenchymal transition (EMT) in gastric cancer cells through the transforming growth factor (TGF)- $\beta$ /mothers against decapentaplegic homolog (Smad) signaling pathway (24). Nevertheless, the role and potential regulatory mechanism of ADAM17 in gastric cancer progression has not been fully elucidated.

The objective of the present study was to identify the role of ADAM17 in regulating gastric cancer metastasis, to investigate its mechanism of action, and to evaluate its clinical significance. In the present study, key members of the ADAM protein family associated with lymph node metastasis in gastric cancers were identified, and the correlation between survival times of patients and their clinicopathological features was investigated. Additionally, the expression of ADAM17 in gastric cancer cells with different metastatic potential was determined and the effects of ADAM17 dysregulation on cell viability, migration, and invasion were explored. Finally, key pathways correlated with ADAM17 were identified using gene set enrichment analysis (GSEA) and confirmed by western blot analysis.

\section{Patients and methods}

Patients. From January 2011 to December 2012, 193 patients (150 males and 43 females) were enrolled at The First Hospital of Jilin University with gastric cancer and positive lymph node metastasis. Patients underwent gastrectomy with D2 lymph node dissection. The diagnosis of was confirmed by histopathological analysis. Patients with distant metastasis, incomplete clinical or pathological data, impaired organ function, other malignant tumors in the previous year, or were undergoing preoperative neoadjuvant chemotherapy/emergency surgery for obstruction and perforation were excluded. A summary of the patient clinical data is presented in Table I. Primary gastric cancer tissues, adjacent non-cancerous gastric tissues, positive metastatic lymph node tissues and corresponding negative metastatic lymph node tissues were obtained, fixed in $10 \%$ formalin at room temperature for $48 \mathrm{~h}$, and embedded in paraffin. The present study was approved by the Research Ethics Boards of The First Hospital of Jilin University, and all patients provided informed consent.

Immunohistochemistry and evaluation of immunostaining intensity. Tissue sections $(4 \mu \mathrm{m})$ cut from the paraffin-embedded samples mentioned above were deparaffinized with xylene and rehydrated with graded xylene and serial ethanol concentrations. For antigen retrieval, the sections were incubated with citrate buffer (0.01 M,pH 6.0) and microwaved at $95^{\circ} \mathrm{C}$ for $10 \mathrm{~min}$. After rinsing thrice with $\mathrm{PBS}(\mathrm{pH} 7.2), 3 \% \mathrm{H}_{2} \mathrm{O}_{2}$ in methanol was used to block endogenous peroxidase activity at room temperature for $15 \mathrm{~min}$. To reduce non-specific reactions, $5 \%$ bovine serum albumin (Gibco; Thermo Fisher Scientific, Inc., Waltham, MA, USA) and $0.3 \%$ Triton X-100 were added and incubated with the sections at room temperature for $1 \mathrm{~h}$. Subsequently, the sections were probed with appropriate antibodies against ADAM8 (1:100; cat. no. 23778-1-AP; ProteinTech Group, Inc., Chicago, IL, USA), ADAM9 (1:75; cat. no. PA5-25959; Thermo Fisher Scientific, Inc.), ADAM10 (1:250; cat no. PA5-28161; Thermo Fisher Scientific, Inc.), ADAM12 (1:100; cat. no. 14139-1-AP), ADAM17 (1:300; cat. no. 20259-1-AP) and GAPDH (1:100; cat. no. 10494-1-AP; all ProteinTech Group, Inc.) overnight at $4^{\circ} \mathrm{C}$. PBS was used as the negative control. Following three rinses with PBS ( $\mathrm{pH} 7.2$ ), the sections were probed with horseradish peroxidase (HRP)-labeled Peroxidase AffiniPure goat anti-rabbit IgG (1:300; cat. no. 111-035-045) or Peroxidase AffiniPure HRP-labeled goat anti-mouse IgG (1:400; cat. no. 115-035-003; both Jackson ImmunoResearch Laboratories, Inc., West Grove, PA, USA) secondary antibodies for $30 \mathrm{~min}$ at room temperature. Following three washes, the sections were stained with 3,3'-diaminobenzidine (cat. no. DA1010; Beijing Solarbio Science \& Technology Co., Ltd., Beijing, China) at room temperature for $1 \mathrm{~min}$, counterstained with hematoxylin (cat. no. 517-28-2; Beijing Solarbio Science \& Technology Co., Ltd.) at room temperature for $50 \mathrm{sec}$, dehydrated with graded concentrations of ethanol and xylene, and coverslipped.

Under a light microscope (magnification, x40), the immunostaining intensity for each protein was reviewed and independently scored by two pathologists who were blinded to the clinical data and scored independently according to the staining intensity and the proportion of stained tumor cells, as previously described (20) with minor modifications. According to the staining intensity, they were scored as follows: No staining $=0$; light yellow (weak staining) $=1$; yellow brown (moderate staining) $=2$; and brown (strong staining) $=3$. The scores were expressed in terms of the proportion of cell staining as follows: scores of $0,1,2,3$ and 4 indicated $0, \leq 25$, $26-50,51-75$, and $\geq 75 \%$ positive cells, respectively. Thus, the two combined scores (from the two independent pathologists) were taken as the final score: 0-1, 2-3, 4-5 and 6-7 indicated negative (-), weak positive $(+)$, strong positive $(++)$, and very strong positive $(+++)$, respectively. In the statistical analysis, $(++)$ and $(+++)$ were classified as the positive group, while $(-)$ and $(+)$ were classified as the negative group.

Cell culture. Human gastric cancer cell lines KATO III and AGS were purchased from the China Center for Type Culture Collection (Wuhan University, Wuhan, China). SGC-7901 and BGC-823 cell lines were obtained from the Shanghai Institute of Cell Biology of the Chinese Academy of Science (Shanghai, China). All cells were grown in RPMI-1640 medium (cat. no. $11995500 \mathrm{BT}$ ) containing $10 \%$ fetal bovine serum (cat. no. 10099-141; both Gibco; Thermo Fisher Scientific, Inc.) and a mixture of penicillin $(100 \mathrm{U} / \mathrm{ml})$ and streptomycin $(100 \mu \mathrm{g} / \mathrm{ml})$ at $37^{\circ} \mathrm{C}$ until $80-90 \%$ confluence.

Cell transfection. The coding sequence of ADAM17 was synthesized by Genewiz, Inc. (Suzhou, China). The overexpressed vector pcDNA-3-ADAM17 was then constructed by inserting the coding sequence of ADAM17 into the pcDNA-3 vector (Invitrogen; Thermo Fisher Scientific, Inc.) with the restriction sites KpnI (GGTACC) and EcoRI (GAATTC). The 
Table I. Univariate analysis of the correlation between clinicopathological factors and survival time of patients with gastric cancer $(n=193)$.

\begin{tabular}{|c|c|c|c|c|c|}
\hline Clinicopathological factors & Category & Cases & Average survival time (days) & Log-rank test & P-value \\
\hline \multirow[t]{2}{*}{ Sex } & Male & 150 & $1,250.625 \pm 71.768$ & \multirow[t]{2}{*}{0.303} & \multirow[t]{2}{*}{0.582} \\
\hline & Female & 43 & $1,347.992 \pm 136.535$ & & \\
\hline \multirow[t]{2}{*}{ Age (years) } & $\leq 60$ & 84 & $1,371.239 \pm 96.847$ & \multirow[t]{2}{*}{1.239} & \multirow[t]{2}{*}{0.266} \\
\hline & $>60$ & 109 & $1,203.797 \pm 84.352$ & & \\
\hline \multirow[t]{3}{*}{ Location of tumor } & Lower third & 111 & $1,256.182 \pm 84.888$ & \multirow[t]{3}{*}{0.033} & \multirow[t]{3}{*}{0.984} \\
\hline & Middle third & 48 & $1,293.933 \pm 131.450$ & & \\
\hline & Upper third & 34 & $1,284.501 \pm 132.457$ & & \\
\hline \multirow[t]{2}{*}{ Tumor cell differentiation } & Poorly differentiated & 118 & $1,188.670 \pm 82.583$ & \multirow[t]{2}{*}{2.154} & \multirow[t]{2}{*}{0.142} \\
\hline & $\begin{array}{l}\text { Moderately } \\
\text { differentiated }\end{array}$ & 75 & $1,409.714 \pm 97.930$ & & \\
\hline \multirow[t]{2}{*}{ Vascular invasion } & No & 23 & $1,975.831 \pm 130.803$ & \multirow[t]{2}{*}{11.517} & \multirow[t]{2}{*}{0.001} \\
\hline & Yes & 170 & $1,176.990 \pm 66.925$ & & \\
\hline \multirow[t]{2}{*}{ Neural invasion } & No & 82 & $1,551.325 \pm 94.354$ & \multirow[t]{2}{*}{13.877} & \multirow[t]{2}{*}{$<0.001$} \\
\hline & Yes & 111 & $1,066.643 \pm 80.522$ & & \\
\hline \multirow[t]{4}{*}{ T staging } & $\mathrm{T} 1$ & 10 & $2,150.600 \pm 173.040$ & \multirow[t]{4}{*}{18.978} & \multirow[t]{4}{*}{$<0.001$} \\
\hline & $\mathrm{T} 2$ & 14 & $1,839.429 \pm 157.060$ & & \\
\hline & $\mathrm{T} 3$ & 155 & $1,188.106 \pm 69.482$ & & \\
\hline & $\mathrm{T} 4$ & 14 & $854.327 \pm 199.427$ & & \\
\hline \multirow[t]{4}{*}{$\mathrm{N}$ staging } & NO & 25 & $2,045.247 \pm 109.148$ & \multirow[t]{4}{*}{46.631} & \multirow[t]{4}{*}{$<0.001$} \\
\hline & $\mathrm{N} 1$ & 59 & $1,513.435 \pm 107.510$ & & \\
\hline & $\mathrm{N} 2$ & 57 & $1,152.316 \pm 114.874$ & & \\
\hline & N3 & 52 & $711.307 \pm 84.118$ & & \\
\hline \multirow[t]{2}{*}{ Drinking } & No & 147 & $1,290.952 \pm 73.459$ & \multirow[t]{2}{*}{0.190} & \multirow[t]{2}{*}{0.663} \\
\hline & Yes & 46 & $1,202.467 \pm 124.052$ & & \\
\hline \multirow[t]{2}{*}{ Smoking } & No & 120 & $1,303.457 \pm 82.993$ & 0.520 & 0.471 \\
\hline & Yes & 73 & $1,210.292 \pm 95.941$ & & \\
\hline Tumor size & $\leq 10$ & 57 & $1,402.576 \pm 118.432$ & 1.809 & 0.179 \\
\hline & $>10$ & 136 & $1,223.221 \pm 75.350$ & & \\
\hline Family history & No & 173 & $1,280.990 \pm 66.943$ & 0.476 & 0.788 \\
\hline & Yes & 19 & $1,232.173 \pm 216.603$ & & \\
\hline Obesity & No & 10 & $1,609.167 \pm 245.612$ & 1.923 & 0.166 \\
\hline & Yes & 178 & $1,255.652 \pm 66.649$ & & \\
\hline ADAM9 & Negative & 2 & $556.500 \pm 123.500$ & 2.524 & 0.112 \\
\hline & Positive & 191 & $1,284.413 \pm 64.362$ & & \\
\hline ADAM17 & Negative & 80 & $1,629.540 \pm 89.506$ & 19.844 & $<0.001$ \\
\hline & Positive & 113 & $996.790 \pm 75.842$ & & \\
\hline
\end{tabular}

ADAM, disintegrin and metalloproteinase domain-containing protein.

empty pcDNA-3 vector served as the control. Small interfering RNAs (siRNAs) targeting ADAM17 (siRNA-ADAM17) and negative control siRNAs (siRNA-NC) were synthesized by Shanghai GenePharma Co., Ltd. (Shanghai, China). The sequences were as follows: siRNA-ADAM17 forward, 5'-GGG CCGAAUAUAACAUAGAdTdT-3' and reverse, 5'-UCUAUG UUAUAUUCGGCCCdTdT-3'; siRNA-NC forward, 5'-UUC UCCGAACGUGUCACGUdTdT-3' and reverse, 5'-ACGUGA CACGUUCGGAGAAdTdT-3'.
These siRNAs were designed using BLOCK-iT ${ }^{\mathrm{TM}}$ RNAi Designer (Thermo Fisher Scientific, Inc.). For cell transfection, SGC-7901 and BGC-823 cells (2.4x10 $/$ well) were seeded into a six-well plate and incubated for $24 \mathrm{~h}$ at $37^{\circ} \mathrm{C}$. Next, $2 \mu \mathrm{g}$ pcDNA-3-ADAM17 and $2 \mu \mathrm{g}$ pcDNA-3 were transfected into BGC-823 cells using Lipofectamine ${ }^{\circledR} 2000$ reagent (cat. no. 11668-027; Invitrogen; Thermo Fisher Scientific, Inc.). si-RNA-ADAM17 (50 nM) BS siRNA-NC (50 nM) were transfected into SGC-7901 cells using the same method. Cells 

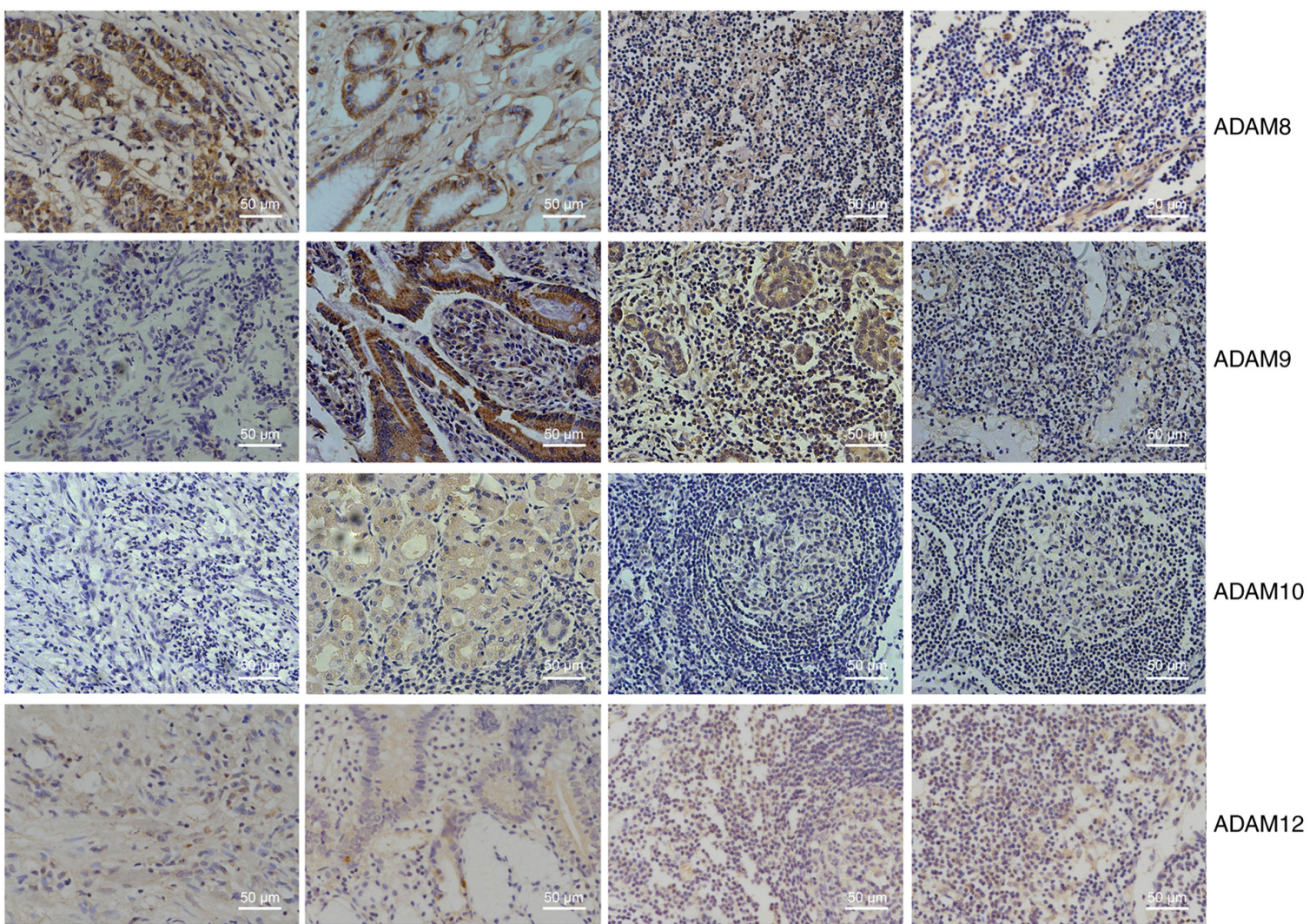

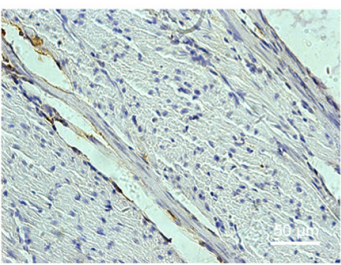

Normal

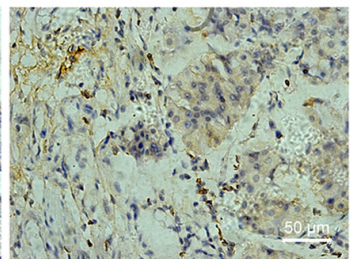

Gastric cancer
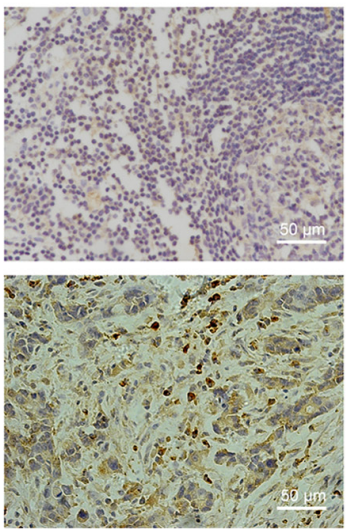

Positive metastatic lymph node

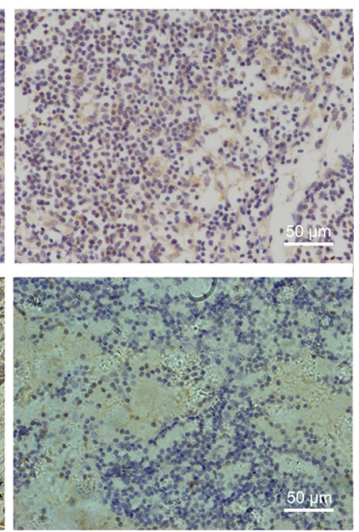

ADAM12

ADAM17

Negative metastatic lymph node

Figure 1. Immunohistochemical analysis showing the expression of ADAM8, ADAM9, ADAM10, ADAM12 and ADAM17 in adjacent non-cancerous gastric tissues, gastric cancer tissues, positive metastatic lymph node tissues, and negative metastatic lymph node tissues. Scale bars, $50 \mu \mathrm{M}$. ADAM, disintegrin and metalloproteinase domain-containing protein.

were incubated for another $48 \mathrm{~h}$ at $37^{\circ} \mathrm{C}$ before performing further experiments.

Reverse transcription-quantitative polymerase chain reaction (RT-qPCR). Total mRNA was extracted from transfected cells using TRIzol reagent (Invitrogen; Thermo Fisher Scientific, Inc.). Reverse transcription of mRNA to cDNA was performed using the PrimeScript RT Master Mix kit (cat. no. RR036A; Takara Bio, Inc., Otsu, Japan) with the following conditions: $37^{\circ} \mathrm{C}$ for $15 \mathrm{sec}, 85^{\circ} \mathrm{C}$ for $5 \mathrm{sec}$; then held at $4^{\circ} \mathrm{C}$. To detect the expression levels of ADAM17 mRNA, qPCR was performed using a SYBR Green kit (cat. no. 4367659; Invitrogen) on an ABI ViiA7 PCR system (both Thermo Fisher Scientific, Inc.). Primers used for the amplification of targets were as follows: ADAM17 forward, 5'-ATCAAACCCTTTCCTGCG-3' and reverse, 5'-CAAACC CATCCTCGTCCA-3'; GAPDH forward, 5'-TGACAACTTTGG TATCGTGGAAGG-3' and reverse, 5'-AGGCAGGGATGA TGTTCTGGAGAG-3'. The thermocycling conditions were as follows: $95^{\circ} \mathrm{C}$ for $10 \mathrm{~min}$, followed by 40 cycles at $95^{\circ} \mathrm{C}$ for $15 \mathrm{sec}$ and $60^{\circ} \mathrm{C}$ for $1 \mathrm{~min}$, and finally $95^{\circ} \mathrm{C}$ for $15 \mathrm{sec}, 60^{\circ} \mathrm{C}$ for $1 \mathrm{~min}$, and $95^{\circ} \mathrm{C}$ for $15 \mathrm{sec}$. The relative expression of ADAM17 mRNA was normalized to GAPDH and was quantified using the $2^{-\Delta \Delta \mathrm{Cq}}$ method (25).

Cell Counting kit-8 (CCK-8) assay. Cells (5x10\% were seeded in a 96-well plate and incubated for $24 \mathrm{~h}$ and were subsequently transfected with pcDNA-3-ADAM17, pcDNA-3, siRNA-ADAM17 or siRNA-NC. Each treatment was performed in triplicate wells. After transfection for $48 \mathrm{~h}$, cell viability of each group was assessed using a CCK-8 kit (cat. no. CK04, Dojindo Molecular Technologies, Inc., Kumamoto, Japan) following the manufacturers' recommended protocols. Absorbance at $450 \mathrm{~nm}$ was measured on a microplate reader (BioTek Instruments, Inc., Winooski, VT, USA).

Scratch wound healing assay. The cell migratory capacity of each group was evaluated using the scratch wound healing assay, as described previously (26). Briefly, transfected cells were seeded in culture dishes in triplicate and were incubated at $37^{\circ} \mathrm{C}$ until a confluent monolayer was formed (>90\%). With a $10 \mu \mathrm{l}$ sterile pipette tip, a 'scratch' of the cell monolayer was 

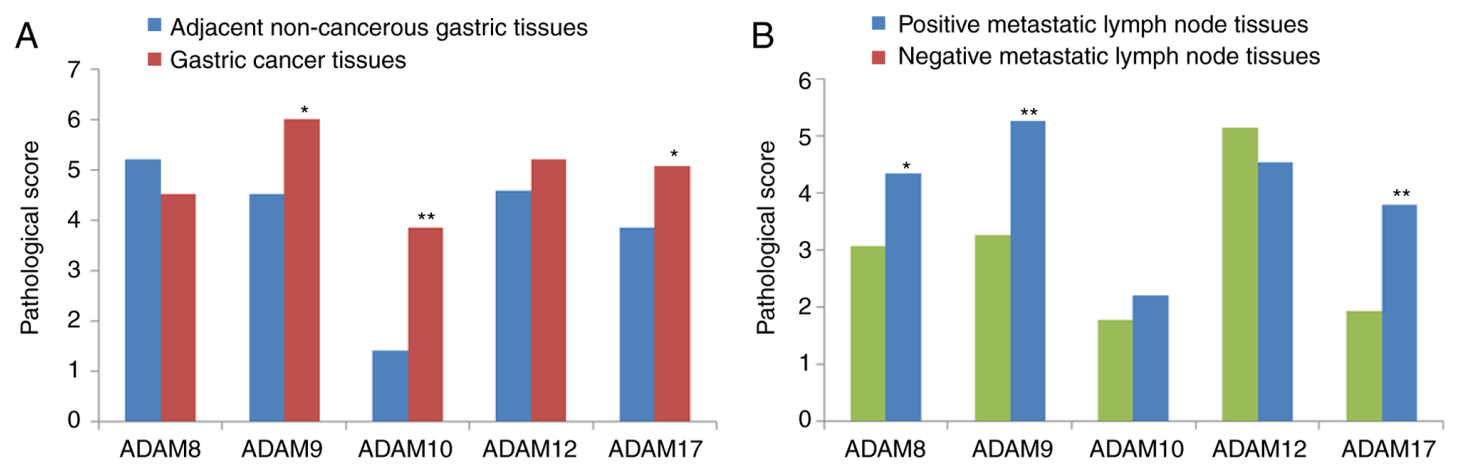

Figure 2. Pathological scores of ADAM8, ADAM9, ADAM10, ADAM12 and ADAM17 expression according to the staining intensity and the percentage of cell staining. (A) Pathological scores of ADAMs in adjacent non-cancerous gastric tissues $(n=15)$ and gastric cancer tissues ( $\mathrm{n}=15)$. (B) Pathological scores of ADAMs in positive metastatic lymph node and negative metastatic lymph node tissues $(\mathrm{n}=15)$. ${ }^{*} \mathrm{P}<0.05,{ }^{* *} \mathrm{P}<0.01$ vs. the corresponding control group. ADAM, disintegrin and metalloproteinase domain-containing protein.

created in a straight line. The cells were washed thrice with PBS (pH 7.2) to remove cell fragments, and the cells were incubated with serum-free RPMI-1640 medium for $24 \mathrm{~h}$ at $37^{\circ} \mathrm{C}$. The migrated cells were observed under an inverted light microscope (Nikon Corporation, Tokyo, Japan).

GSEA of gastric cancer expression. GSEA (www.broadinstitute.org/gsea/index.jsp) (27) is a computational method for interpreting gene expression data; it creates a molecular signature database based on known information on the positions, characteristics and biological functions of genes. To investigate the role of ADAM17 in gastric cancer, mRNA sequence data of stomach adenocarcinoma from The Cancer Genome Atlas (TCGA; tcga-data.nci.nih.gov/) was downloaded, which included 415 stomach adenocarcinoma samples. Key pathways that were enriched by gene sets significantly associated with ADAM17 were then analyzed by GSEA, and $\mathrm{P}<0.05$ was set as the cut-off value.

Western blot analysis. Total protein was extracted from gastric cancer tissues and cells using radioimmunoprecipitation assay buffer (cat. no. PL007; Sangon Biotech Co., Ltd., Shanghai, China) for $20 \mathrm{~min}$ on ice. Protein concentration was determined with bicinchoninic acid protein assay kit (cat no. 23223; Pierce; Thermo Fisher Scientific, Inc.). For western blotting, protein extracts (30 $\mu \mathrm{g} / \mathrm{lane}$ ) were subjected to $10 \%$ SDS-PAGE and transferred onto a polyvinylidene fluoride membrane. Following blocking in $1 \mathrm{X}$ Tris-buffered saline $/ 0.05 \%$ Tween-20 (TBST) supplemented with 5\% non-fat milk at room temperature for $1 \mathrm{~h}$, primary antibodies against ADAM17 (1:1,000; cat. no. 20259-1-AP; ProteinTech Group, Inc.), ADAM9 (1:1,000; cat. no. PA5-25959; Thermo Fisher Scientific, Inc.), neurogenic locus notch homolog protein (Notch)2 (1:1,000; cat. no. WL02409; Wanleibio Co., Ltd., Shanghai, China); glycogen synthase kinase (GSK)-3 $\beta$ (1:1,000; cat. no. 22104-1-AP; ProteinTech Group, Inc.), $\beta$-catenin (1:1,000; cat. no. 8480S; Cell Signaling Technology, Inc., Danvers, MA, USA) or $\beta$-actin (1:2,000; cat. no. 60008-1-Ig; ProteinTech Group, Inc.) were added to the membranes and incubated overnight at $4^{\circ} \mathrm{C} . \beta$-actin was used as the internal control. After washing with 1X PBST thrice, HRP-labeled Peroxidase AffiniPure goat anti-rabbit $\operatorname{IgG}(1: 5,000$; cat. no. 111-035-045; Jackson ImmunoResearch Laboratories, Inc.) or Peroxidase AffiniPure goat anti-mouse IgG HRP (1:5,000; cat. no. 115-035-003; Jackson ImmunoResearch Laboratories, Inc.) was added to the membranes and incubated at room temperature for another $2 \mathrm{~h}$. After rinsing five times with 1X PBST, protein bands were visualized using chemiluminescent HRP substrate (cat. no. WBKLS0500; Merck KGaA, Darmstadt, Germany). The intensity of each protein band was quantified and analyzed using Tanon Image Software version 1.10 (Tanon 1600R; Tanon Science and Technology Co., Ltd., Shanghai, China).

Statistical analysis. Univariate survival analysis for the comparison of survival times was conducted using the Kaplan-Meier method, and the log-rank test was applied to analyze the significance of difference between survival times of patients and their clinicopathological features, as well as between survival times and ADAM9 or ADAM17 expression. Multivariate survival analysis was performed for identifying significant variables associated with survival times using the Cox regression proportional hazards model. In addition, the risk scores of death were calculated with multivariate logistic regression analysis (28) According to the T staging, $\mathrm{N}$ staging and ADAM17 values, the risk score of each patient (ranging from 0 to 100) was calculated. The receiver operating characteristic (ROC) curve was applied, and the area under the curve (AUC) was determined by the MedCalc statistical software version 11.0 (MedCalc, Mariakerke, Belgium). Data were presented as the mean \pm standard deviation, and the differences between two groups were compared using the Student's t-test and among three or more groups were analyzed by one-way analysis of variance, followed by Fisher's least significant difference test. Statistical analyses were carried out using SPSS 17.0 (SPSS, Inc., Chicago, IL, USA). P $<0.05$ was considered to indicate a statistically significant difference.

\section{Results}

ADAM9 and ADAM17 are significantly upregulated in gastric cancer and positive metastatic lymph node tissues. Fig. 1 shows the immunohistochemical staining intensity for ADAM8, ADAM9, ADAM10, ADAM12 and ADAM17 in adjacent non-cancerous gastric tissues, gastric cancer tissues, positive metastatic lymph node tissues and negative metastatic lymph node tissues. From the combined score that 
A

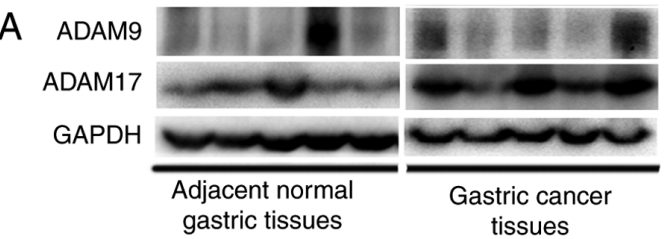

Adjacent normal gastric tissues

$x$

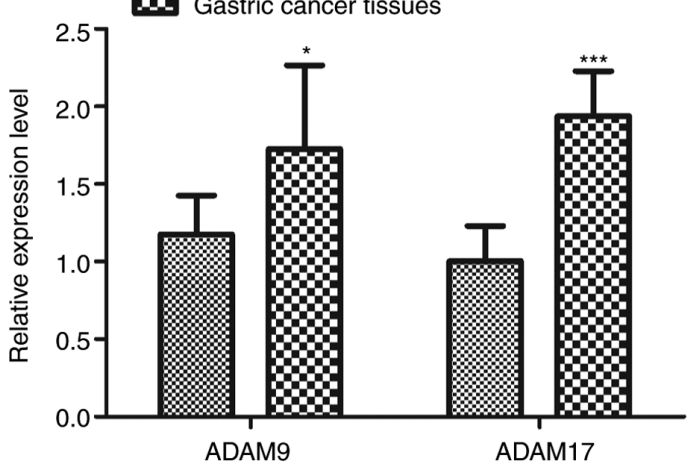

B
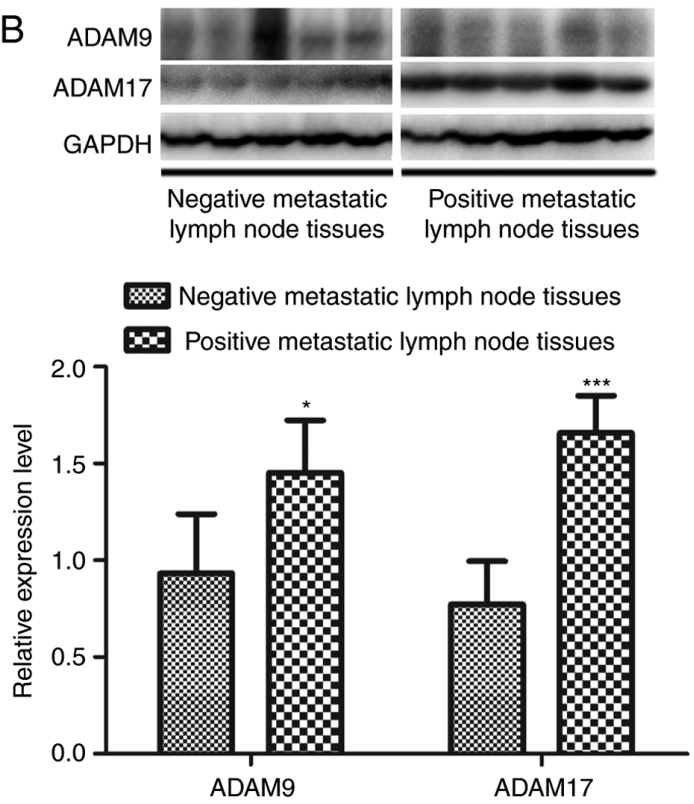

Figure 3. Relative expression of ADAM9 and ADAM17 in different tissues was examined by western blotting. (A) ADAM9 and ADAM17 expression in adjacent non-cancerous gastric tissues $(n=5)$ and gastric cancer tissues $(n=5)$. (B) ADAM9 and ADAM17 in positive ( $\mathrm{n}=5)$ and negative metastatic lymph node tissues $(n=5) .{ }^{*} \mathrm{P}<0.05,{ }^{* * * *} \mathrm{P}<0.001$ vs. the corresponding control group. ADAM, disintegrin and metalloproteinase domain-containing protein.

was obtained from the staining intensity and the percentage of cell staining, the expression of ADAM9, ADAM10, and ADAM17 in gastric tumor tissues was significantly upregulated compared to those in adjacent normal tissues $(\mathrm{P}<0.05$; Fig. 2A). Furthermore, the expression of ADAM8, ADAM9 and ADAM17 in positive metastatic lymph node tissues was also upregulated relative to those in the corresponding negative tissues $(\mathrm{P}<0.05$; Fig. $2 \mathrm{~B})$. These data indicated that ADAM9 and ADAM17 were significantly upregulated in both gastric cancer and positive metastatic lymph node tissues. To further verify the immunohistochemistry results, the expression of ADAM9 and ADAM17 was detected by western blotting. As expected, ADAM9 and ADAM17 expression was significantly upregulated in primary gastric tumor tissues and positive metastatic lymph node tissues ( $\mathrm{P}<0.05$; Fig. 3).

Survival times of patients correlated with T staging, N staging, and ADAM17 expression. Univariate survival analysis for the comparison of survival times between patients with clinicopathological features was performed. As presented in Table I, the survival times of patients were significantly associated with vascular invasion, neural invasion, T staging, $\mathrm{N}$ staging and ADAM17 expression $(\mathrm{P}<0.05)$. Therefore, multivariate analysis was used to identify significant clinicopathological features associated with survival times. The results demonstrated that the survival times of patients strongly correlated with $\mathrm{T}$ staging, $\mathrm{N}$ staging and ADAM17 expression $(\mathrm{P}<0.05$; Table II). Furthermore, multivariate logistic regression analysis showed similar results that the above three variables were independent predictors $(\mathrm{P}<0.05$; Table III). The above three variables were then included in the 'risk score' calculation to measure the 'mortality risk score' of any given patients, as follows: Probability $=1 /[1+\exp$ [5.454-0.993 (T staging)-0.720 (N staging)-0.771 (ADAM17)]].
The distribution of the risk score of 193 patients is presented in Fig. 4. The majority of scores were distributed between 60 and $100(60-80, n=89 ; 80-100, n=43$; Fig. 4A), suggesting that this model can separate the low- and high-risk groups, and the risk of mortality increased with the increase in risk scores (Fig. 4B). To further determine the optimal model to predict the risk of death, ROC curve analysis was performed. As shown in Table IV and Fig. 4C, the AUCs for the risk score model, $\mathrm{T}$ staging, $\mathrm{N}$ staging, and ADAM17 expression were $0.757,0.625,0.720$ and 0.618 , respectively. These data indicated that $\mathrm{T}$ staging, $\mathrm{N}$ staging and ADAM17 expression had independent prognostic value for predicting the risk of patients with gastric cancer.

ADAM17 was highly expressed in gastric cancer cells with high metastatic potential. Next, the expression of ADAM7 in gastric cancer cells was determined. As shown in Fig. 5A, ADAM17 expression in KATO III and SGC-7901 cells that had high metastatic potential was significantly higher than that in BGC-823 and AGS cells with low metastatic potential, suggesting that ADAM17 may be associated with tumor cell metastasis. Among the above four cell lines, ADAM17 expression was lowest in BGC-823 cells and highest in SGC-7901 cells. Therefore, BGC-823 and SGC-7901 cells were used for the overexpression and repression of ADAM17 expression, respectively. As expected, ADAM17 expression was significantly increased in pcDNA-3-ADAM17-transfected BGC-823 cells, compared with mock cells or pcDNA-3-transfected cells $(\mathrm{P}<0.05$; Fig. $5 \mathrm{~B})$, while its expression was markedly reduced in siRNA-ADAM17-transfected SGC-7901 cells compared with either mock cells or siRNA-NC-transfected cells $(\mathrm{P}<0.05$; Fig. 5C).

ADAM17 promotes the viability and migration of gastric cancer cells. The effects of ADAM17 on cell viability in each group was assessed using the CCK-8 assay. As 
Table II. Multivariate survival analysis of gastric cancer (Cox proportional hazards model).

\begin{tabular}{lccrrrr}
\hline Covariates & Variable coefficient & Standard error & Wald & P-value & HR & 95\% CI \\
\hline ADAM17 & 0.806 & 0.199 & 16.430 & $<0.001$ & 2.239 & $1.516-3.305$ \\
T staging (T2/3/4 vs. T1) & 0.598 & 0.192 & 9.677 & 0.002 & 1.818 & $1.248-2.650$ \\
N staging (N1/2/3 vs. N0) & 0.543 & 0.104 & 27.147 & $<0.001$ & 1.722 & $1.404-2.113$ \\
Vascular invasion & 0.408 & 0.406 & 1.009 & 0.315 & 1.504 & $0.678-3.336$ \\
Neural invasion & 0.092 & 0.211 & 0.193 & 0.661 & 1.097 & $0.726-1.658$ \\
\hline
\end{tabular}

HR, hazard ratio; CI, confidence interval; ADAM, disintegrin and metalloproteinase domain-containing protein.

Table III. Independent predictors of lymph node metastasis based on the multivariate logistic regression analysis.

\begin{tabular}{lccrrrrr}
\hline & \multicolumn{1}{l}{$\begin{array}{l}\text { Regression } \\
\text { Variable(s) }\end{array}$} & $\begin{array}{c}\text { Standard } \\
\text { error }\end{array}$ & Wald & P-value & OR & Lower & Upper \\
\hline T staging & 0.993 & 0.350 & 8.052 & 0.005 & 2.700 & 1.360 & 5.362 \\
N staging & 0.720 & 0.184 & 15.338 & $<0.001$ & 2.055 & 1.433 & 2.947 \\
ADAM17 & 0.771 & 0.338 & 5.207 & 0.022 & 2.161 & 1.115 & 4.190 \\
Constant & -5.454 & 1.203 & 20.569 & $<0.001$ & 0.004 & &
\end{tabular}

OR, odds ratio; CI, confidence interval; ADAM, disintegrin and metalloproteinase domain-containing protein.
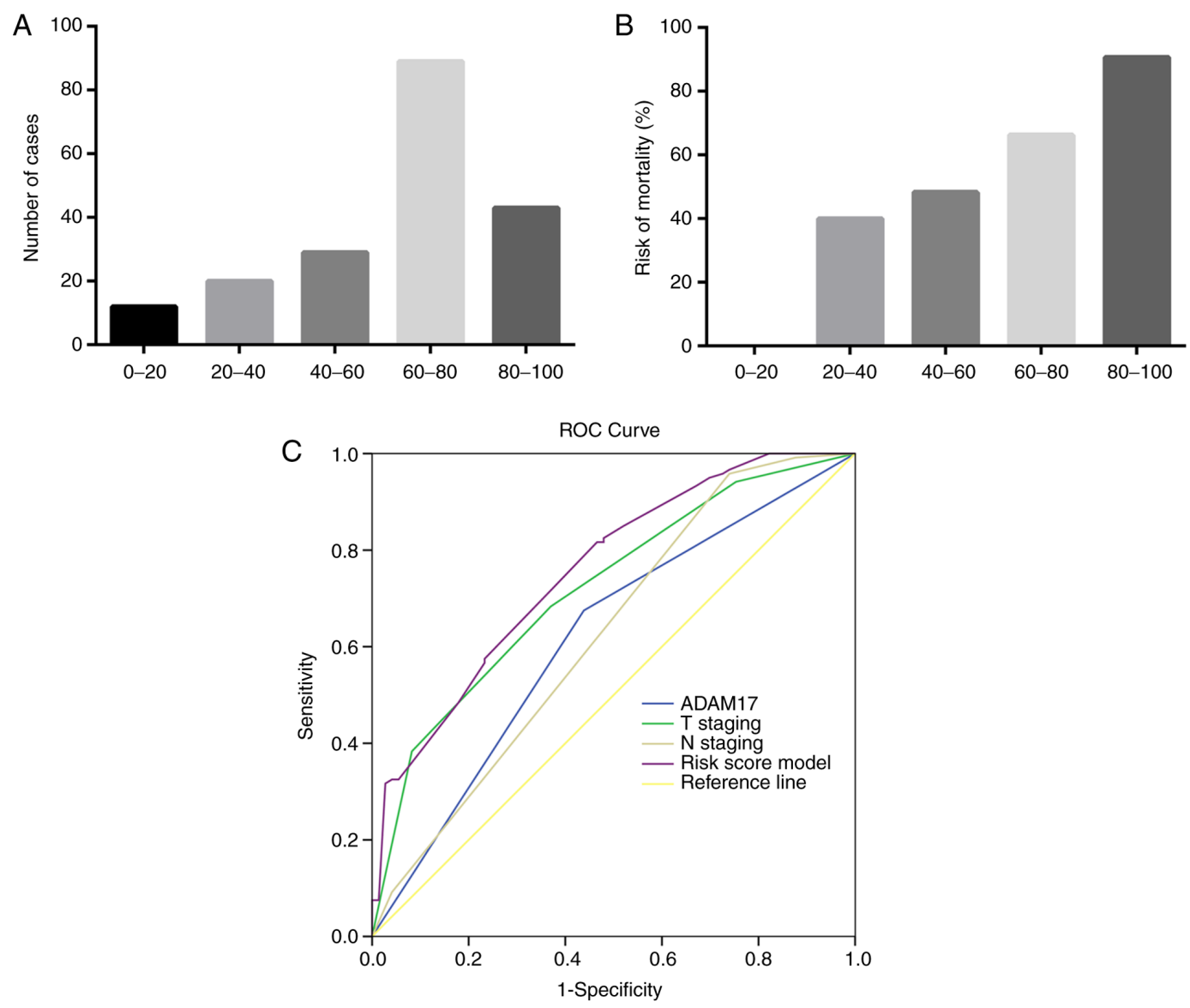

Figure 4. Correlation of mortality risk scores in 193 patients. (A) The number of patients distributed across different risk score ranges. (B) Mortality incidence was correlated with the risk score. The results showed that the higher the risk scores, the greater is the risk of mortality. (C) Receiver operating characteristic curves of different predictors for mortality risk. Four predictors, including the risk score model, $\mathrm{T}$ staging, $\mathrm{N}$ staging and ADAM17 expression, were included in the analysis. ADAM, disintegrin and metalloproteinase domain-containing protein. 
Table IV. Analysis of AUC of different predictors for mortality risk.

$95 \%$ Confidence Interval

\begin{tabular}{lccccc} 
Test variable & AUC & $\begin{array}{c}\text { Standard } \\
\text { error }\end{array}$ & P-value & Lower bound & Upper bound \\
\hline ADAM17 & 0.618 & 0.042 & 0.006 & 0.536 & 0.701 \\
T staging & 0.625 & 0.043 & 0.004 & 0.541 & 0.709 \\
N staging & 0.720 & 0.037 & 0.000 & 0.648 & 0.793 \\
Risk score model & 0.757 & 0.035 & $<0.001$ & 0.688 & 0.826 \\
\hline
\end{tabular}

Risk score model vs. ADAM17, $\mathrm{P}=0.0001$; risk score model vs. T staging, $\mathrm{P}=0.0004$; risk score model vs. $\mathrm{N}$ staging, $\mathrm{P}=0.1742$. AUC, area under the curve.
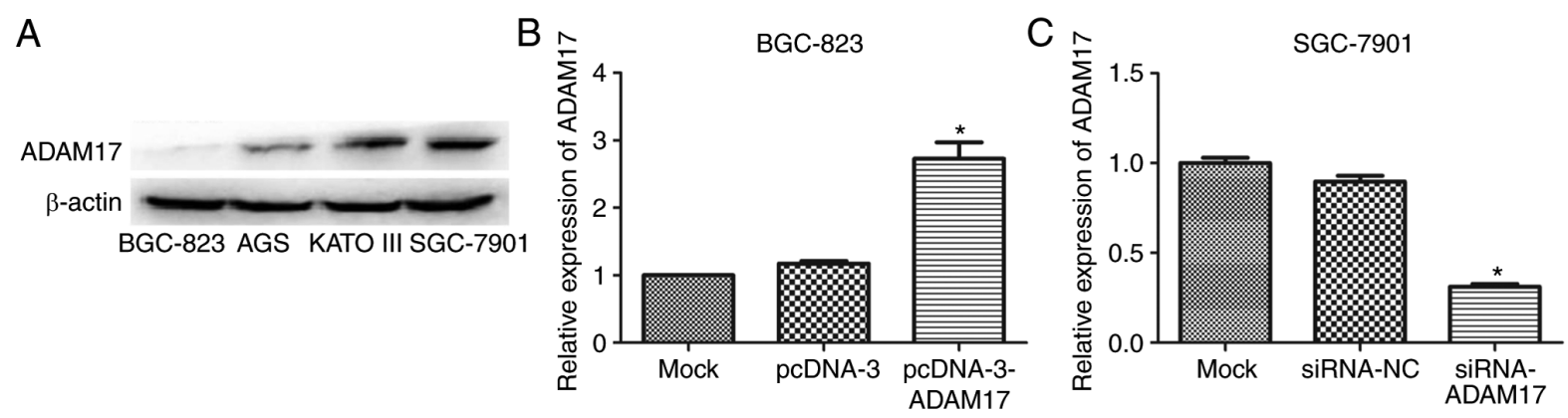

Figure 5. Expression of ADAM17 in gastric cancer cells. (A) western blotting showed the expression of ADAM17 in BGC-823, AGS, KATO III and SGC-7901 cells. (B) ADAM17 expression in mock-transfected cells, pcDNA-3-transfected, or pcDNA-3-ADAM17-transfected BGC-823 cells. (C) ADAM17 expression in mock-transfected, siRNA-NC-transfected or siRNA-ADAM17-transfected SGC-7901 cells. All experiments were repeated three times and data are presented as the mean \pm standard deviation. ${ }^{*} \mathrm{P}<0.05$ vs. corresponding control group. ADAM, disintegrin and metalloproteinase domain-containing protein; siRNA, small interfering RNA; NC, negative control.

presented in Fig. 6A, the overexpression of ADAM17 in pcDNA-3-ADAM17-transfected BGC-823 cells resulted in a significant increase in cell viability, compared with mock cells or pcDNA-3-transfected cells $(\mathrm{P}<0.05)$. However, the cell viability of siRNA-ADAM17-transfected SGC-7901 cells was significantly reduced compared with the mock or siRNA-NC transfected cells $(\mathrm{P}<0.05$; Fig. 6B). Next, the scratch wound healing assay was performed to study the effects of ADAM17 on cell migration. It was revealed that the number of migrated SGC-7901 cells was significantly decreased following ADAM17 silencing $(\mathrm{P}<0.05$; Fig. 6D). However, the migratory capacity between pcDNA-3-ADAM17-transfected BGC-823 cells, mock cells and pcDNA-3-transfected cells did not show significant difference ( $\mathrm{P}>0.05$; Fig. 6C). Taken together, these results suggested that ADAM17 promoted gastric cancer cell viability and migration.

GSEA for analyzing ADAM17 function in gastric cancer. The results of GSEA revealed 12 pathways, including the Notch and Wnt signaling pathways (Fig. 7), that positively correlated with ADAM17 expression (Table V). Furthermore, 19 pathways associated with metabolism, including oxidative phosphorylation and phenylalanine metabolism, were negatively correlated with ADAM17 expression (Table V).

Suppression of ADAM17 in SGC-7901 cells inhibits Notch and Wnt signaling pathways. To further verify the results of GSEA, western blot analysis was performed to investigate the expression of key proteins involving in Notch and Wnt signaling pathways in SGC-7901 cells following the suppression of ADAM17 expression. The results demonstrated that suppression of ADAM17 in SGC-7901 cells resulted in a significant downregulation of Notch2, GSK-3 $\beta$ and $\beta$-catenin expression (Fig. 8), suggesting that suppression of ADAM17 in SGC-7901 cells inhibited the Notch and/or Wnt signaling pathways.

\section{Discussion}

Tumor metastasis is one of the main causes of treatment failure among patients with cancer, and ADAMs have been implicated in tumor metastasis and progression (29). Therefore, a better understanding of the key members of the ADAM family that are involved in gastric cancer progression will facilitate the development of a promising therapeutic regimen.

In the present study, ADAM17 was found to be significantly upregulated in gastric cancer and positive metastatic lymph node tissues. Consistent with previous findings reporting that ADAM17 is an independent prognostic factor for patients with gastric cancer (23), a strong correlation was identified between the survival time of patients and ADAM17 expression, confirming that ADAM17 could be used as an independent prognostic factor. In addition, it was shown that ADAM17 was upregulated in gastric cancer cells with high metastatic potential. Notably, ADAM17 overexpression significantly increased BGC-823 cell viability with low metastatic potential, while the 

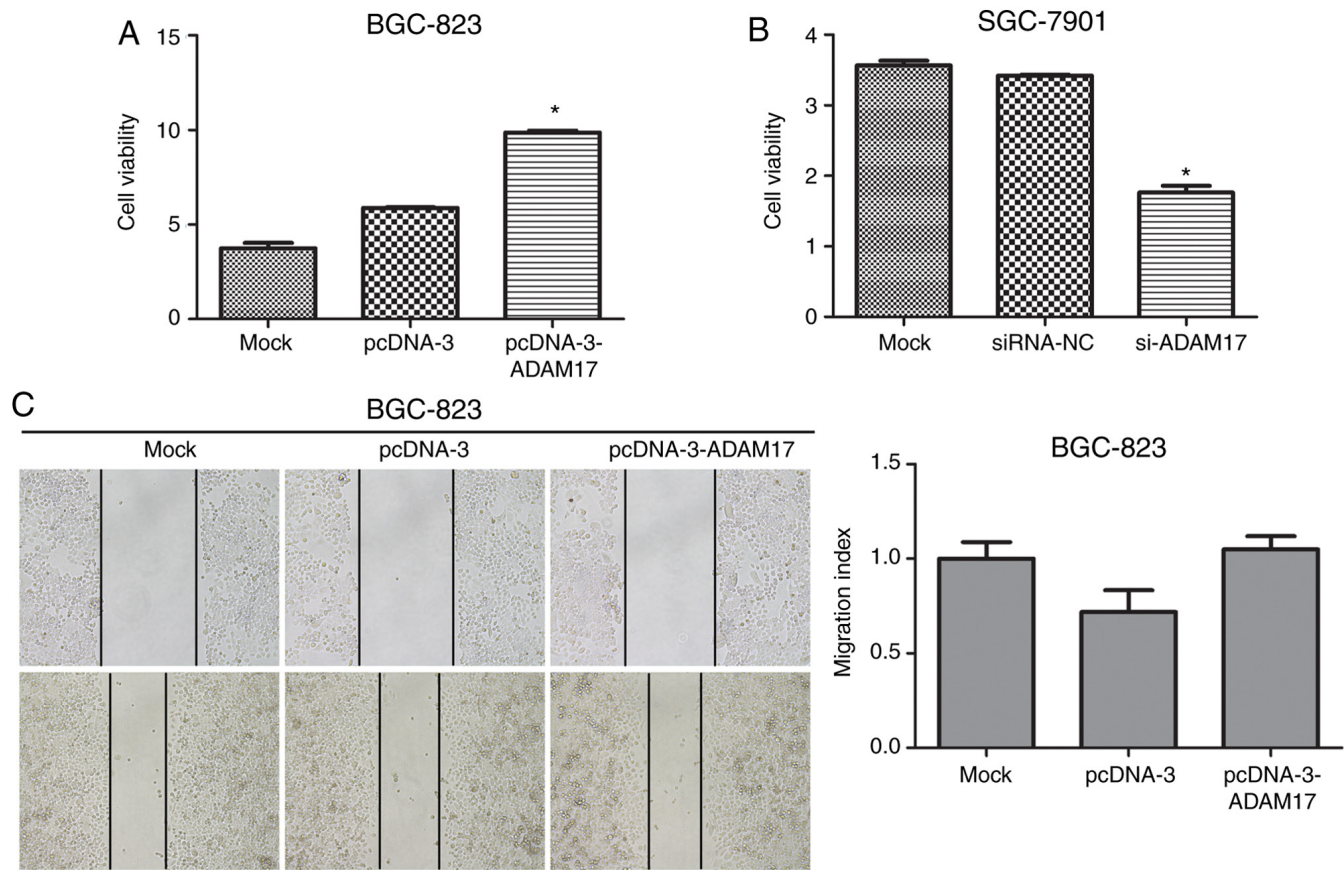

D
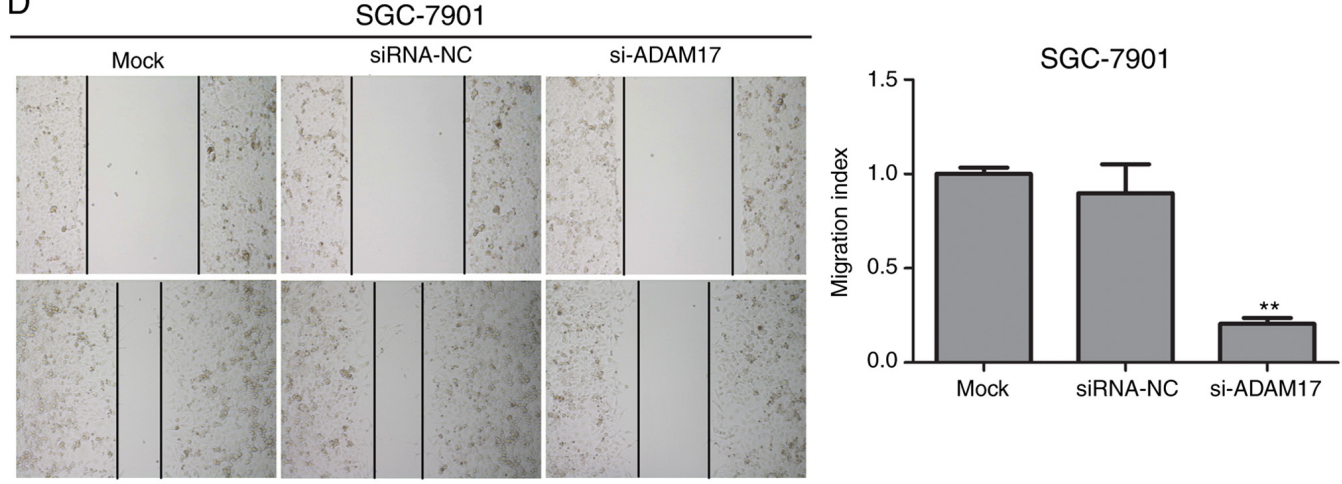

Figure 6. Effects of ADAM17 overexpression and suppression on cell viability and migration. (A and B) Cell Counting kit-8 assays showed the cell viability of transfected (A) BGC-823 and (B) SGC-7901 cells. (C and D) Scratch wound healing assay showed cell migration of transfected (C) BGC-823 and (D) SGC-7901 cells. All experiments were repeated three times and data are presented as the mean \pm standard deviation. ${ }^{*} \mathrm{P}<0.05$ and ${ }^{* *} \mathrm{P}<0.01$ vs. corresponding control group. ADAM, disintegrin and metalloproteinase domain-containing protein; siRNA, small interfering RNA; NC, negative control.

Enrichment plot: KEGG_NOTCH_SIGNALING_PATHWAY

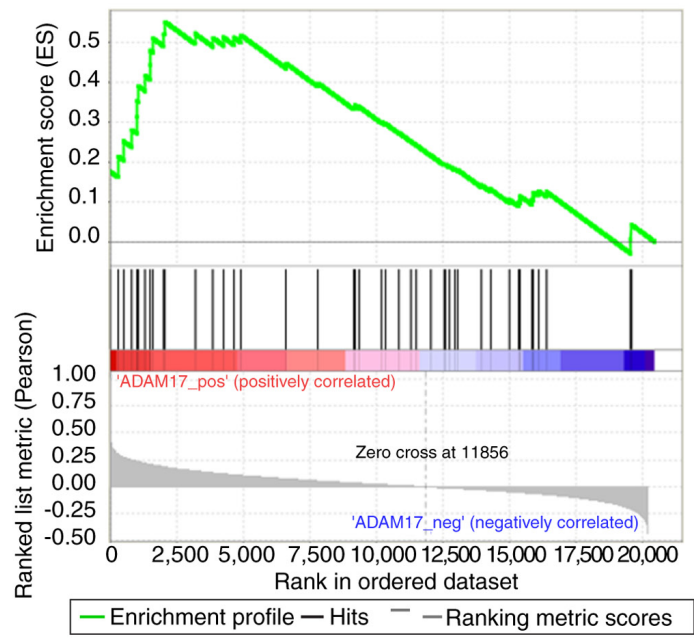

Enrichment plot: KEGG_WNT_SIGNALING_PATHWAY

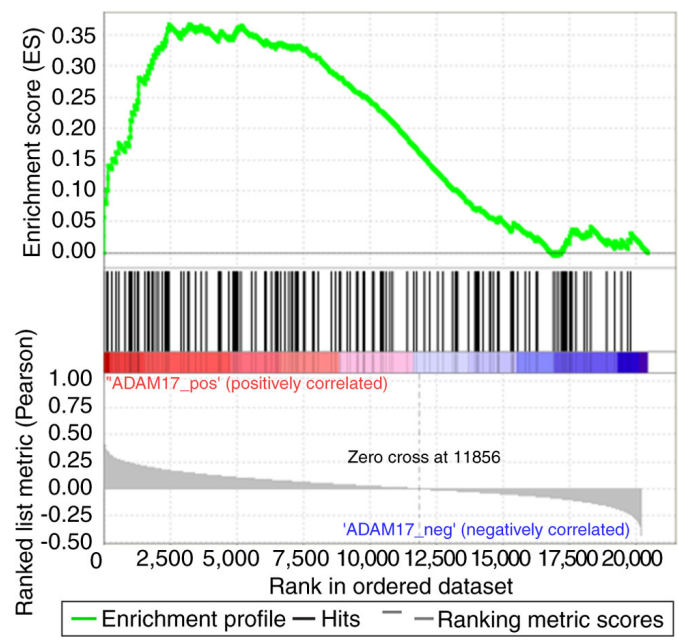

Figure 7. Gene set enrichment analysis showed the enrichment plots of gene expression signatures for the Notch or Wnt signaling pathway according to ADAM17 expression. The barcode plot indicates the positions of genes in each gene set; red and blue colors indicate positive and negative correlations with ADAM17 expression, respectively. ADAM, disintegrin and metalloproteinase domain-containing protein; KEGG, Kyoto Encyclopedia of Genes and Genomes; Notch, neurogenic locus notch homolog protein. 
Table V. Results of gene set enrichment analysis showed key pathways correlated with ADAM17 expression in gastric cancer.

Name Size ES NES P-value

A, Positively correlation with ADAM17 expression

\begin{tabular}{lrrrr}
\hline Notch signaling pathway & 47 & 0.55082 & 1.91005 & 0.00178 \\
Ubiquitin-mediated proteolysis & 134 & 0.45800 & 1.82770 & 0.00180 \\
Small cell lung cancer & 84 & 0.44413 & 1.66057 & 0.00361 \\
Adherens junction & 73 & 0.43867 & 1.62956 & 0.01235 \\
Glycosaminoglycan biosynthesis heparan sulfate & 26 & 0.53938 & 1.60466 & 0.02632 \\
ErbB signaling pathway & 87 & 0.41745 & 1.58098 & 0.02330 \\
Prostate cancer & 89 & 0.40135 & 1.57703 & 0.01431 \\
Pathways in cancer & 324 & 0.35638 & 1.56122 & 0.01165 \\
Progesterone-mediated oocyte maturation & 85 & 0.40244 & 1.54025 & 0.01783 \\
Renal cell carcinoma & 70 & 0.40003 & 1.51718 & 0.03209 \\
Axon guidance & 128 & 0.39454 & 1.51392 & 0.03375 \\
Wnt signaling pathway & 149 & 0.36756 & 1.49736 & 0.02993 \\
\hline
\end{tabular}

B, Negative correlation with ADAM17 expression

\begin{tabular}{|c|c|c|c|c|}
\hline Parkinson's disease & 113 & -0.78448 & -2.33212 & $<0.001$ \\
\hline Oxidative phosphorylation & 116 & -0.77444 & -2.23988 & $<0.0001$ \\
\hline Huntington's disease & 172 & -0.62239 & -2.23308 & 0.00217 \\
\hline Alzheimer's disease & 156 & -0.61537 & -2.22474 & 0.00221 \\
\hline Cardiac muscle contraction & 73 & -0.54398 & -2.06387 & 0.00236 \\
\hline Ribosome & 87 & -0.84358 & -2.01567 & 0.00408 \\
\hline Primary bile acid biosynthesis & 16 & -0.62983 & -1.80464 & 0.01307 \\
\hline Phenylalanine metabolism & 18 & -0.56414 & -1.72816 & 0.01659 \\
\hline Peroxisome & 78 & -0.4785 & -1.72701 & 0.01379 \\
\hline Glutathione metabolism & 50 & -0.5088 & -1.70551 & 0.01235 \\
\hline Linoleic acid metabolism & 28 & -0.50486 & -1.69893 & 0.01566 \\
\hline Tryptophan metabolism & 39 & -0.46789 & -1.68343 & 0.02103 \\
\hline Citric acid cycle & 30 & -0.61788 & -1.67656 & 0.04651 \\
\hline Drug metabolism cytochrome $\mathrm{p} 450$ & 71 & -0.47023 & -1.67642 & 0.02727 \\
\hline Tyrosine metabolism & 42 & -0.43363 & -1.64599 & 0.01232 \\
\hline Metabolism of xenobiotics by cytochrome p450 & 69 & -0.46883 & -1.63288 & 0.03529 \\
\hline Histidine metabolism & 28 & -0.45888 & -1.58055 & 0.02778 \\
\hline Fatty acid metabolism & 42 & -0.49172 & -1.57598 & 0.04292 \\
\hline Arachidonic acid metabolism & 57 & -0.39434 & -1.50295 & 0.04798 \\
\hline
\end{tabular}

Size, the number of gene enriched in each pathway; ES, enrichment score; NES, normalized enrichment score; ADAM, disintegrin and metalloproteinase domain-containing protein.

knockdown of ADAM17 reduced the viability and migratory capacity of SGC-7901 cells, which have high metastatic potential. Furthermore, GSEA revealed a strong positive correlation between ADAM17 expression and the Notch/Wnt signaling pathways. Further experiments confirmed that suppression of ADAM17 in SGC-7901 cells inhibited the Notch and Wnt signaling pathways.

Metastasis is a multistep process mediating the progression of malignant tumors, in which cell-cell and cell-matrix interactions are implicated. These interactions result in the activation of numerous cytokines and growth factors and the subsequent generation of signals to promote tumor growth and survival (30). ADAM17 affects various growth factors, cytokines, receptors, and cell adhesion molecules, which are all broadly involved in regulating the proliferation, migration and invasion of tumor cells (31). Because angiogenesis is essential for tumor growth and metastasis $(32,33)$, and ADAM17 is a central regulator of angiogenesis (34), ADAM17 may also influence tumor angiogenesis and invasion (35). ADAM17 promotes the malignant phenotype of U87 human glioma cells by increasing their proliferation and invasion (36), and the silencing of ADAM17 significantly suppresses the proliferation and invasion of A549 cells in vitro (37). Furthermore, a previous report confirmed that ADAM17 is highly expressed 

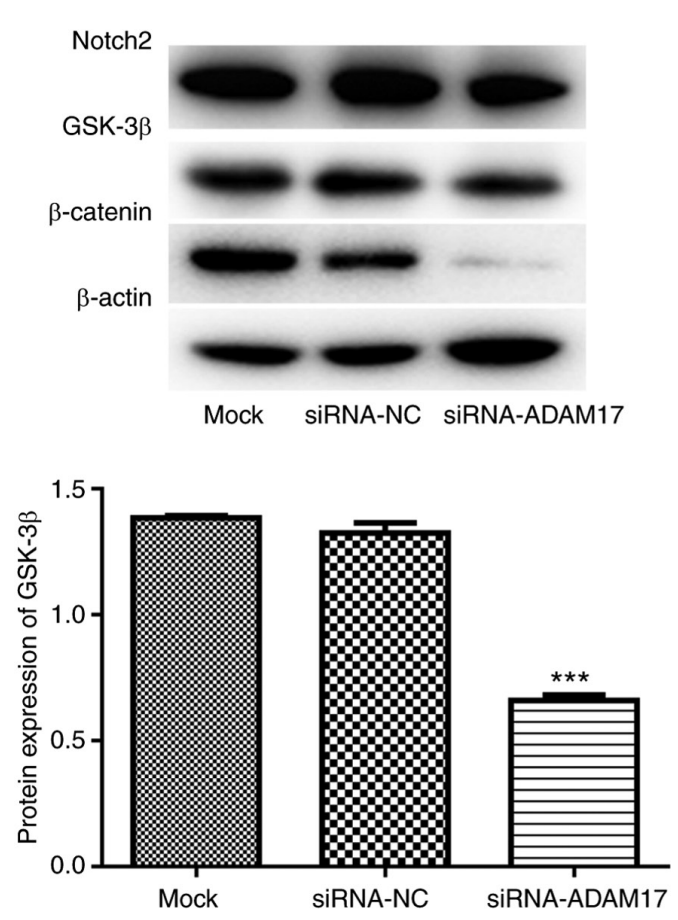
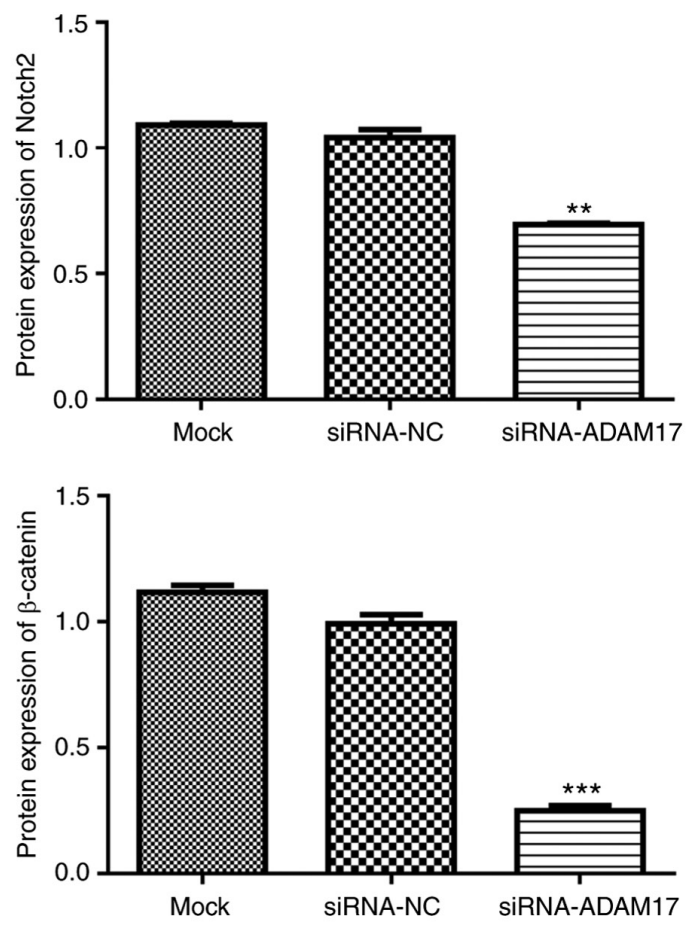

Figure 8. Western blot analysis of Notch2, GSK-3 $\beta$, and $\beta$-catenin protein expression in SGC-7901 cells following suppression of ADAM17. All experiments were repeated three times and data are presented as the mean \pm standard deviation. ${ }^{* *} \mathrm{P}<0.01,{ }^{* * *} \mathrm{P}<0.001$ vs. the NC group. ADAM, disintegrin and metalloproteinase domain-containing protein; Notch, neurogenic locus notch homolog protein; GSK-3 $\beta$, glycogen synthase kinase-3 $\beta$; siRNA, small interfering RNA; NC, negative control.

in lymph node-positive breast cancer tissues in comparison with lymph node-negative tissues (38), implying the association between ADAM17 and lymph node metastasis. Notably, ADAM17 has been shown to prevent the miR-338-3p-mediated inhibition of gastric cancer cell migration and invasion (22). $\mathrm{Xu}$ et al (24) demonstrated that ADAM17 promotes EMT in gastric cancer cells through the TGF- $\beta /$ Smad pathway, and an increasing number of studies have indicated that EMT is a phenotypic conversion associated with cancer metastasis $(39,40)$. In the present study, ADAM17 was found to be upregulated in gastric cancer and lymph node-positive gastric cancer tissues. In addition, ADAM17 was upregulated in gastric cancer cells with high metastatic potential. Importantly, ADAM17 silencing decreased the viability and migratory capacity of SGC-7901 cells with high metastatic potential. However, ADAM17 overexpression only increased the viability of BGC-823 cells, and did not promote the migratory capacity, which may be due to their low metastatic potential. Taken together, it was speculated that the ADAM17 upregulation facilitated the metastasis of gastric cancer by promoting cell viability and migration.

The increased expression of ADAM17 is closely correlated with poor prognosis in many human cancers, such as gallbladder carcinoma (41) and breast cancer (42) and may serve as a poor prognostic factor $(43,44)$. ADAM17 expression also has prognostic significance in patients with gastric cancer $(21,45)$. Furthermore, ADAM17 is considered to be a potential target in anticancer treatment or as an indicator for predicting therapeutic outcomes (42). Kyula et al (46) demonstrated that chemotherapy with fluorouracil acutely activates ADAM17 and consequently results in drug resistance in colorectal cancer. In line with these previous findings, the results of the multivariate analysis performed in the present study showed a strong correlation between the survival time of patients and the expression of ADAM17. Therefore, it was hypothesized that increased expression of ADAM17 may have been involved in poor gastric cancer prognosis, and that it may serve as an independent prognostic marker. Targeting ADAM17 may have prospects in cancer prognosis and therapy.

GSEA and western blotting revealed a positive correlation between ADAM17 expression and the Notch and Wnt signaling pathways. An aberration in Notch signaling results in the metastasis of various cancers via the regulation of EMT or tumor angiogenesis (47). A meta-analysis confirmed that the Notch signaling pathway is a key pathway for mediating tumor progression in gastric cancer (48). Brzozowa et al (49) revealed that the Notch signaling pathway serves a key role in the pathogenesis of gastric cancer. In addition, the Wnt signaling pathway is closely correlated with lung cancer and bone metastasis (50), and $\mathrm{Wnt} / \beta$-catenin signaling regulates tumor metastasis in breast cancer $(51,52)$. Yanaka et al $(53)$ revealed that the activation of the Wnt signaling pathway is a key mechanism in mediating miR-544a-induced EMT to regulate gastric cancer progression. Tan et al (54) confirmed that dixin promotes the metastasis of gastric cancer via activation of the Wnt signaling pathway. Given the key role of the Notch and Wnt signaling pathways in the metastasis and progression of gastric cancer, it was speculated that these pathways are key mechanisms by which ADAM17 mediates its effects in gastric cancer.

However, the current study had several limitations. First, the clinical sample size used was relatively small and not sufficient. More samples should be collected to confirm the results. Second, almost all patients were on adjuvant therapy; 
thus, it was difficult to clearly verify whether ADAM17 was a pure prognostic factor. Third, an invasion assay was not performed to evaluate the function of ADAM17 in the cell invasion ability. An invasion assay should be performed to evaluate the function of ADAM17 in cell invasion ability in future studies, which will provide strong evidence supporting the role of ADAM17 in gastric cancer metastasis and progression. Lastly, the relationship between ADAM17 and Notch or Wnt signaling pathway was only preliminarily confirmed in SGC-7901 cells. More studies are still required to verify these findings.

In conclusion, the data in the present study demonstrated that increased ADAM17 expression may have contributed to gastric cancer metastasis and progression, potentially via activation of the Notch or Wnt signaling pathways, and that ADAM17 may serve as a useful prognostic marker in the treatment of gastric cancer.

\section{Acknowledgements}

Not applicable.

\section{Funding}

The present study was supported by the National Natural Science Foundation of China (grant nos. 81402374 and 81372295) and Excellent Young Foundation of Jilin Scientific and Technological Development Program (grant no. 20170520002JH).

\section{Availability of data and materials}

All data generated or analyzed during this study are included in this published article.

\section{Authors' contributions}

WL, JS and DW contributed to the study design. WL, LW and YZ collected the data and performed the experiments. WL and XS interpreted and discussed the data. WL and DW analyzed the data. WL drafted the manuscript. All authors read and approved the final manuscript.

\section{Ethics approval and consent to participate}

The present study was approved by the Research Ethics Boards of The First Hospital of Jilin University, and all patients provided informed consent.

\section{Patient consent for publication}

Not applicable.

\section{Competing interests}

The authors declare that they have no competing interests.

\section{References}

1. Carcas LP: Gastric cancer review. J Carcinogenesis 13: 14, 2013.
2. Siegel R, Ma J, Zou Z and Jemal A: Cancer statistics, 2014. CA Cancer J Clin 64: 9-29, 2014.

3. Guggenheim DE and Shah MA: Gastric cancer epidemiology and risk factors. J Surg Oncol 107: 230-236, 2013.

4. Wadhwa R, Taketa T, Sudo K, Blum MA and Ajani JA: Modern oncological approaches to gastric adenocarcinoma. Gastroenterol Clin North Am 42: 359-369, 2013.

5. Lee JH, Kim Y, Choi JW and Kim YS: Genetic variants and risk of gastric cancer: A pathway analysis of a genome-wide association study. Springerplus 4: 215, 2015.

6. Ang TL and Fock KM: Clinical epidemiology of gastric cancer. Singapore Med J 55: 621-628, 2014.

7. Lordick F, Kang YK, Chung HC, Salman P, Oh SC, Bodoky G, Kurteva G, Volovat C, Moiseyenko VM, Gorbunova V, et al: Capecitabine and cisplatin with or without cetuximab for patients with previously untreated advanced gastric cancer (EXPAND): A randomised, open-label phase 3 trial. Lancet Oncol 14: 490-499, 2013.

8. Coburn NG: Lymph nodes and gastric cancer. J Surg Oncol 99: 199-206, 2009.

9. Wildeboer D, Naus S, Amy Sang QX, Bartsch JW and Pagenstecher A: Metalloproteinase disintegrins ADAM8 and ADAM19 are highly regulated in human primary brain tumors and their expression levels and activities are associated with invasiveness. J Neuropathol Exp Neurol 65: 516-527, 2006.

10. Reiss K and Saftig P: The 'a disintegrin and metalloprotease' (ADAM) family of sheddases: Physiological and cellular functions. Semin Cell Dev Biol 20: 126-137, 2009.

11. Kim KE, Song H, Hahm C, Yoon SY, Park S, Lee HR, Hur DY, Kim T, Kim CH, Bang SI, et al: Expression of ADAM33 is a novel regulatory mechanism in IL-18-secreted process in gastric cancer. J Immunol 182: 3548-3555, 2009.

12. Carl-Mcgrath S, Lendeckel U, Ebert M, Roessner A and Röcken C: The disintegrin-metalloproteinases ADAM9, ADAM12, and ADAM15 are upregulated in gastric cancer. Int J Oncol 26: 17-24, 2005.

13. Wang YY, Ye ZY, Li L, Zhao ZS, Shao QS and Tao HQ: ADAM 10 is associated with gastric cancer progression and prognosis of patients. J Surg Oncol 103: 116-123, 2011.

14. Murphy G: The ADAMs: Signalling scissors in the tumour microenvironment. Nat Rev Cancer 8: 929-941, 2008.

15. Gall SML, Bobé P, Reiss K, Horiuchi K, Niu XD, Lundell D, Gibb DR, Conrad D, Saftig P and Blopel CP: ADAMs 10 and 17 represent differentially regulated components of a general shedding machinery for membrane proteins such as transforming growth factor alpha, L-selectin, and tumor necrosis factor alpha. Mol Biol Cell 20: 1785-1794, 2009.

16. Lorenzen I, Trad A and Grötzinger J: Multimerisation of A disintegrin and metalloprotease protein-17 (ADAM17) is mediated by its EGF-like domain. Biochem Biophys Res Commun 415: 330-336, 2011.

17. Ni SS, Zhang J, Zhao WL, Dong XC and Wang JL: ADAM17 is overexpressed in non-small cell lung cancer and its expression correlates with poor patient survival. Tumour Biol 34: 1813-1818, 2013.

18. Franovic A, Robert I, Smith K, Kurban G, Pause A, Gunaratnam L and Lee S: Multiple acquired renal carcinoma tumor capabilities abolished upon silencing of ADAM17. Cancer Res 66: 8083-8090, 2006.

19. Shen H, Li L, Zhou S, Yu D, Yang S, Chen X, Wang D, Zhong S, Zhao J and Tang J: The role of ADAM17 in tumorigenesis and progression of breast cancer. Tumour Biol, 2016.

20. Shou ZX, Jin $X$ and Zhao ZS: Upregulated expression of ADAM17 is a prognostic marker for patients with gastric cancer. Ann Surg 256: 1014-1022, 2012.

21. Zhang TC, Zhu WG, Huang MD, Fan RH and Chen XF: Prognostic value of ADAM17 in human gastric cancer. Med Oncol 29: 2684-2690, 2012.

22. Chen JT, Yao KH, Hua L, Zhang LP, Wang CY and Zhang JJ: MiR-338-3p inhibits the proliferation and migration of gastric cancer cells by targeting ADAM17. Int J Clin Exp Pathol 8: 10922-10928, 2015.

23. Fang W, Qian J, Wu Q, Chen Y and Yu G: ADAM-17 expression is enhanced by FoxM1 and is a poor prognostic sign in gastric carcinoma. J Surg Res 220: 223-233, 2017.

24. Xu M, Zhou H, Zhang C, He J, Wei H, Zhou M, Lu Y, Sun Y, Ding JW,Zeng J, et al: ADAM17 promotes epithelial-mesenchymal transition via TGF- $\beta /$ Smad pathway in gastric carcinoma cells. Int J Oncol 49: 2520-2528, 2016. 
25. Livak KJ and Schmittgen TD: Analysis of relative gene expression data using real-time quantitative PCR and the 2(-Delta Delta C(T)) method. Methods 25: 402-408, 2001

26. Cory G: Scratch-wound assay. Methods Mol Biol 769: 25-30, 2011.

27. Subramanian A, Tamayo P, Mootha VK, Mukherjee S, Ebert BL, Gillette MA, Paulovich A, Pomeroy SL, Golub TR, Lander ES and Mesirov JP: Gene set enrichment analysis: A knowledge-based approach for interpreting genome-wide expression profiles. Proc Natl Acad Sci USA 102: 15545-15550, 2005.

28. Marrelli D, De StefanoA, de Manzoni G, Morgagni P, Di Leo A and Roviello F: Prediction of recurrence after radical surgery for gastric cancer: A scoring system obtained from a prospective multicenter study. Ann Surg 241: 247-255, 2005.

29. Torres-Collado AX and Iruela-Arispe ML: Contribution of ADAMs and ADAMTSs to tumor expansion and metastasis In: Cancer Genome and Tumor Microenvironment. Andrei Thomas-Tikhonenko (ed.). Springer; New York, NY, pp 293-314, 2010.

30. Yu CC, Tsai LL, Wang ML, Yu CH, Lo WL, Chang YC, Chiou GY, Chou MY and Chiou SH: miR145 targets the SOX9/ADAM17 axis to inhibit tumor-initiating cells and IL-6-mediated paracrine effects in head and neck cancer. Cancer Res 73: 3425-3440, 2013.

31. Mėżyk-Kopeć R, Wyroba B, Stalińska K, Próchnicki T, Wiatrowska K, Kilarski WW, Swartz MA and Bereta J: ADAM17 promotes motility, invasion, and sprouting of lymphatic endothelial cells. PLoS One 10: e0132661, 2015.

32. Saaristo A, Karpanen T and Alitalo K: Mechanisms of angiogenesis and their use in the inhibition of tumor growth and metastasis. Oncogene 19: 6122-6129, 2000.

33. Jiang BH and Liu LZ: PI3K/PTEN signaling in tumorigenesis and angiogenesis. Biochim Biophys Acta 1784: 150-158, 2008.

34. Gooz P, Gooz M, Baldys A and Hoffman S: ADAM_17: A central regulator of angiogenesis. Matrix Biology 25: S55-S56, 2006

35. Klein $\mathrm{T}$ and Bischoff $\mathrm{R}$ : Active metalloproteases of the A Disintegrin and Metalloprotease (ADAM) family: Biological function and structure. J Proteome Res 10: 17-33, 2011.

36. Zheng X, Jiang F, Katakowski M, Lu Y and Chopp M: ADAM17 promotes glioma cell malignant phenotype. Mol Carcinog 51: 150-164, 2012

37. Lv X, Li Y, Qian M, Ma C, Jing H, Wen Z and Qian D: ADAM17 silencing suppresses the migration and invasion of non-small cell lung cancer. Mol Med Rep 9: 1935-1940, 2014.

38. Mcgowan PM, Ryan BM, Hill AD, Mcdermott E, O'Higgins N and Duffy MJ: ADAM-17 expression in breast cancer correlates with variables of tumor progression. Clin Cancer Res 13: 2335-2343, 2007.

39. Thiery JP, Acloque H, Huang RY and Nieto MA: Epithelialmesenchymal transitions in development and disease. Cell 139 . 871-890, 2009

40. Xiang J, Fu X, Ran W and Wang Z: Grhl2 reduces invasion and migration through inhibition of TGF $\beta$-induced EMT in gastric cancer. Oncogenesis 6: e284, 2017.

41. Wu K, Liao M, Liu B and Deng Z: ADAM-17 over-expression in gallbladder carcinoma correlates with poor prognosis of patients. Med Oncol 28: 475, 2011.
42. McGowan PM, Mckiernan E, Bolster F, Ryan BM, Hill AD Mcdermott EW, Evoy D, O'Higgins N, Crown J and Duffy MJ: ADAM-17 predicts adverse outcome in patients with breast cancer. Ann Oncol 19: 1075-1081, 2008.

43. Gooz M: ADAM-17: The enzyme that does it all. Crit Rev Biochem Mol Biol 45: 146-169, 2010.

44. Rose-John S: ADAM17, shedding, TACE as therapeutic targets. Pharmacol Res 71: 19-22, 2013.

45. Aydin D, Bilici A, Yavuzer D, Kefeli U, Tan A, Ercelep O, Mert A, Yuksel S, Ozcelik M, Isik D, et al: Prognostic significance of ADAM17 expression in patients with gastric cancer who underwent curative gastrectomy. Clin Transl Oncol 17: 604-611, 2015.

46. Kyula JN, Schaeybroeck SV, Doherty J, Fenning CS, Longley DB and Johnston PG: Chemotherapy-induced activation of ADAM-17: A novel mechanism of drug resistance in colorectal cancer. Clin Cancer Res 16: 3378-3389, 2010.

47. Hu YY, Zheng MH, Zhang R, Liang YM and Han H: Notch signaling pathway and cancer metastasis. Adv Exp Med Biol 727: 186-198, 2012.

48. Du X, Cheng Z, Wang YH, Guo ZH, Zhang SQ, Hu JK and Zhou ZG: Role of Notch signaling pathway in gastric cancer: A meta-analysis of the literature. World J Gastroenterol 20: 9191-9199, 2014

49. Brzozowa M, Mielańczyk Ł, Michalski M, Malinowski Ł, Kowalczyk-Ziomek G, Helewski K, Harabin-Słowińska M and Wojnicz R: Role of Notch signaling pathway in gastric cancer pathogenesis. Contemp Oncol (Pozn) 17: 1-5, 2013.

50. Xi Y and Chen Y: Wnt signaling pathway: Implications for therapy in lung cancer and bone metastasis. Cancer Lett 353: $8-16,2014$

51. Cai J, Guan H, Fang L, Yang Y, Zhu X, Yuan J, Wu J and Li M: MicroRNA-374a activates Wnt/ $\beta$-catenin signaling to promote breast cancer metastasis. J Clin Invest 123: 566-579, 2013.

52. Jang GB, Kim JY, Cho SD, Park KS, Jung JY, Lee HY, Hong IS and Nam JS: Blockade of Wnt/ $\beta$-catenin signaling suppresses breast cancer metastasis by inhibiting CSC-like phenotype. Sci Rep 5: 12465, 2015.

53. Yanaka Y, Muramatsu T, Uetake H, Kozaki KI and Inazawa J: miR-544a induces epithelial-mesenchymal transition through the activation of WNT signaling pathway in gastric cancer. Carcinogenesis 36: 1363-1371, 2015.

54. Tan C, Qiao F, Wei P, Chi Y, Wang W, Ni S, Wang Q, Chen T, Sheng W, Du X and Wang L: DIXDC1 activates the Wnt signaling pathway and promotes gastric cancer cell invasion and metastasis. Mol Carcinog 55: 397-408, 2016.

This work is licensed under a Creative Commons Attribution-NonCommercial-NoDerivatives 4.0 International (CC BY-NC-ND 4.0) License. 